\title{
Chapter 6 \\ Disease Protection in Sea Coast (and \\ Inland) Cities: Problems in Dense \\ Populations with Shantytowns/Slums
}

\subsection{Introduction}

As discussed earlier in this book, there are sea coast cities worldwide that are at risk from floods, storm surges, and extreme weather conditions such as wind-driven high category hurricanes (typhoons, monsoons), or drought and heat waves, plus along Pacific Ocean coasts, earthquakes and tsunamis. A municipality and its public health services have to be prepared to adapt to their preparations to deal with what contemporary experiences and history reveal are the most likely physical hazards and diseases to impact it. The two main preparatives are first to be able to care for the injured during a hazard event at well-staffed and supplied hospitals and medical clinics or field hospitals. The second is to fill the basic needs of affected populations with clean water, food, shelter, toilets, waste collection, and if necessary power restoration. These primary responses will help to reduce the chance of an onset and spread of disease. It is important to activate search and rescue teams help citizens isolated or trapped by the event that did not or could not evacuate such as in the case of extreme weather and flooding. In addition, where there have been deaths, bodies should be recovered and interred as soon as possible in order to prevent sickness that might originate from them. For instances of collapsed structures with people trapped inside, equipment that can move debris and rescue people or recover the deceased is necessary as would be the case for less common strong earthquakes as well as some extreme storm events. What was just described may be a good template to follow, but in reality, many sea coast cities in developing and less developed countries do not have the resources to cope with severe hazards that might impact them. Here, the World Health Organization and developed nations, large and small, have sent in personnel, supplies, and equipment to help an impacted sea coast city (or inland city) in the past and will surely continue to do so in the future. 


\subsubsection{Disease Control}

Disease control after a natural disaster often means initially dealing with diarrheal diseases (dysentery) from the ingestion of contaminated water or food, and lack of sanitation facilities (toilets, hand-washing stations). It may mean dealing with cases of the infectious diseases like cholera (bacterium Vibrio cholera) or typhoid (bacterium Salmonella typhi) that originate from contaminated water or food or from contacts with cholera or typhoid carriers. To prevent a spreading epidemic status means making safe water and food, sanitation and hand-washing posts available. In the case of cholera, an epidemic may be avoided by isolating the cholera carriers and treating them (with hydration and antibiotics) or oral cholera vaccines where the disease is endemic until the threat of spread is under control. During March 15-16, 2019, the monsoon Idai flood ravaged Beira, Mozambique, a sea coast city of 533,000 people, and tracked inland into areas of Zimbabwe and Malawi flooding them and killing a total of over 1000 people. In Beira, the drinking water supply and the sewage infrastructure were damaged. Cholera cases were diagnosed and the disease spread rapidly with over 4000 cases identified with 7 deaths by the April 9 . The WHO assembled more 975,000 doses of cholera vaccine (oral) and starting April 3 delivered more than 487,000 initial doses to Beira citizens and those in other affected populations, but only about 2 weeks after the disease was first diagnosed. A second inoculation 2 weeks later gives full protection from the disease. Adaptation would require vaccine storage stations set up in regions where outbreaks of endemic and other infectious diseases occur so that those that can be controlled by vaccination could be serviced more rapidly than was the case in Mozambique.

\subsection{Infectious Diseases}

In the above section, infectious diseases that could follow natural disasters that affect sea coast cities were discussed. In this section, infectious diseases that can affect sea coast cities by developing from within or those that are carried in from outside sources are considered. These would be water- and food-borne contaminants and vector-borne bacteria/viruses (by insects, animals, humans). Important factors that have to be considered by public health personnel in sea coast cities in order to be prepared to deal with disease include a location's latitude and elevation as they influence climate (temperature and humidity).

\subsubsection{Sea Coast City Climate Zones and Endemic Diseases}

Important sea coast cities are located in most geographic climatic zones. As such, and based on a history of urban health problems, their populations may be susceptible to one or more than one infectious disease that public health services should be 
prepared to treat. Six principal climate zones (Mediterranean, tropical, arid, temperate, polar, and mountainous) are classified on the basis of average monthly temperature and precipitation. Temperature and precipitation are determined in grand part by latitude, altitude/landform, and the influence of surface and subsurface ocean currents flow paths, location of mountains and their elevations, and seasonal wind directions. The principal zones are a simplification of a 12 zone classification, each with sub-zones (Table 6.1) [1]. Missing from this classification is a mountainous one because with their masses and elevations they establish their own micro-zones and affect weather patterns of some of the other zones.

Sea coast cities in a similar stage of economic development and in the same climate zones are likely to have exposure to a similar group of endemic infectious diseases. For example, in Southeast Asia, Jakarta, Bangkok, and Ho Chi Minh City, are hot $\left(30{ }^{\circ} \mathrm{C}\right)$ with higher humidity $(75 \% \mathrm{RH})$ and have endemic infectious diseases that originate from contaminated water and food, and those that originate from vector-borne carriers. Country reports show that in the endemic infectious group, all live with the threat of bacterial diarrheal diseases, and two cities live with the threat of Hepatitis A and typhoid fever. In the second group, the three cities have

Table 6.1 Twelve zone, multi-sub-zone climate classification [1]

\begin{tabular}{|c|c|}
\hline Rainforest & High rainfall $\left(175-200 \mathrm{~cm}\right.$ annually, mean monthly temperature $\left.>18^{\circ} \mathrm{C}\right)$ \\
\hline $\begin{array}{l}\text { Monsoon, } \\
\text { typhoon, } \\
\text { hurricane }\end{array}$ & $\begin{array}{l}\text { Seasonal regional rainy season (North and South America, Sub-Saharan } \\
\text { Africa, Australia, and East Asia) }\end{array}$ \\
\hline Tropical savanna & $\begin{array}{l}\text { Semi-arid to semi-humid regions in sub-tropical and tropical latitudes with } \\
\text { temperature at or }>18^{\circ} \mathrm{C} \text { with rainfall between } 75 \text { and } 127 \mathrm{~cm} \text { annually } \\
\text { (widespread in Africa, found in India, and northern parts of South America, } \\
\text { Malaysia, and Australia) }\end{array}$ \\
\hline $\begin{array}{l}\text { Humid } \\
\text { sub-tropical }\end{array}$ & $\begin{array}{l}\text { Winter rainfall mainly from thunderstorms. Mainly on east side of } \\
\text { continents between about } 20^{\circ} \text { and } 40^{\circ} \text { latitudes away from the equator }\end{array}$ \\
\hline $\begin{array}{l}\text { Humid } \\
\text { continental }\end{array}$ & $\begin{array}{l}\text { Large seasonal temperature range with } 3 \text { months of temperatures }>10^{\circ} \mathrm{C} \\
\text { and coldest month temperature }<-3{ }^{\circ} \mathrm{C}\end{array}$ \\
\hline Oceanic climate & $\begin{array}{l}\text { Along west coasts of all continents at middle altitudes and in SE Australia } \\
\text { with lot of precipitation year-round }\end{array}$ \\
\hline $\begin{array}{l}\text { Mediterranean } \\
\text { climate }\end{array}$ & $\begin{array}{l}\text { Hot, dry summers and cold, wet winters. Mediterranean Basin countries, } \\
\text { western North America, parts of Western South Australia, SW South Africa }\end{array}$ \\
\hline Desert & $\begin{array}{l}\text { Little precipitation (dry), large temperature range daily (up to } 45^{\circ} \mathrm{C} \text { and } \\
\text { down to } 0{ }^{\circ} \mathrm{C} \text { ) and seasonally hot, during day, cold during night, all year } \\
\text { except Antarctica }\end{array}$ \\
\hline Steppe & $\begin{array}{l}\text { Dry with temperature that can range from } 40{ }^{\circ} \mathrm{C} \text { during the summer to } \\
-40^{\circ} \mathrm{C} \text { during the winter }\end{array}$ \\
\hline Subarctic climate & $\begin{array}{l}\text { Little precipitation and with permafrost. Temperatures of }>10^{\circ} \mathrm{C} \text { for } \\
1-3 \text { months and for } 6 \text { winter months }<0{ }^{\circ} \mathrm{C}\end{array}$ \\
\hline Tundra & $\begin{array}{l}\text { In the far Northern Hemisphere especially in extensive areas of northern } \\
\text { Russia and Canada. Very cold all year }\end{array}$ \\
\hline Polar icecap & Dry, very cold, all year \\
\hline
\end{tabular}


exposure to dengue fever and malaria while two are threatened by Japanese encephalitis, and one with HIV/AIDS and tuberculosis.

In Africa, Mombasa, Kenya in East Africa, population 537,000 and Luanda, Angola in West Africa, population 2.5 million, are located relatively close to the equator $\left(4^{\circ} 3^{\prime} \mathrm{S}\right.$ and $8^{\circ} 50^{\prime} \mathrm{S}$, respectively) and have similar temperatures of $25-3{ }^{\circ} \mathrm{C}$ and $60-65 \%$ relative humidity defining their Mediterranean/sub-tropical to hot humid tropical climates. However, unlike the Southeast Asian sea coast cities with similar infectious disease burdens cited above, Mombasa and Luanda infectious disease burdens differ greatly. Mombasa residents are at risk from malaria, tuberculosis, HIV/AIDs and recently from a resurgent occurrence of polio, measles, and kanazaar (parasitic disease Leishmania donovani). Luanda, Angola residents are at risk from yellow fever, malaria, typhoid fever, and Hepatitis A. Mombasa, an important Kenyan port city also serves Uganda, Rwanda, the Eastern region of the DR Congo. This put the Mombasa population at risk of infectious diseases that may be carried from those countries by people or products. This possibility for infectious disease transfer was supported when public health personnel recently identified an Ebola strain in Kenyans who visited West Africa. The West African region had suffered an Ebola epidemic during 2013-2016. The disease likely began in a village of southeast Guinea as a young boy infected by bats (bushmeat) was carried by exposed villagers to its capital and port city Conakry (population $1.8+$ million). The Ebola virus was spread by carriers to the Liberian capital and port city Monrovia (population 1 million with 41 doctors), and to the Sierra Leone capital and port city Freetown (population 1+ million). The World Health Organization, medical teams and NGOs from other nations worked to stop the epidemic but only after more than 11,300 died and more than 28,000 were infected and saved. An as-yet unapproved Ebola vaccine was used here and was instrumental in halting the spread of the Ebola virus.

Major sea coast cities in South America and the Indian sub-continent have similarities and differences of infectious disease risks as do the sea coast cities Mombasa and Luanda cited above. Public health services staffed with appropriate personnel, supported financially, with medicine stocks plus WHO vaccination stores can be prepared to use them to halt the spread of an infectious disease to prevent an epidemic or to deal with an epidemic that may develop. On August 1, 2018, there was an outbreak of Zaire Ebola virus in North Kivu province of the DR Congo that spread to Ituri Province. In March, 2019, WHO reported that there were more than 1029 cases and 642 deaths. The public health ministry medical experts identified the disease, did contact tracing, contained and treated infected people, and worked to educate the threatened populations of the risk of not reporting Ebola cases, and unsafe burial practices (touching and washing the dead) that is meeting cultural resistance. As important in dealing with the epidemic was the acceptance of the use of the experimental Ebola vaccine that helped stop the spread of the Ebola disease in West Africa a few years earlier. The vaccine was given to 3300 people who had direct or indirect contact with people with the disease. However, the application of the Ebola vaccine and a halt in the rise of infections has been hampered by armed group violence and unsafe burial practices. The disease is recurrent in the DR Congo 
with ten outbreaks since the discovery of the disease in 1976 [2]. The hope is that it will not become entrenched.

One adaptation to infectious disease prevention in this time of ready transnational transport of people globally via sea, air, and land is vaccination control. Vaccinations against infectious diseases keep a nation healthy and productive. A low rate of vaccination in a country or regions for years on end can be damning to its citizens and to people where they travel within that country or internationally. The WHO warns that vaccine hesitancy is one of the top ten global threats of 2019. Vaccination hesitancy can be the result of personal philosophical or religious beliefs that allow parents to opt out of this protection for their children as in the United States where there have been major measles outbreaks in eight states and reported cases in 20 other states. In many of these states legislatures are proposing laws to minimize exemptions to measles vaccination requirements for children of school age. A judge in Brooklyn, New York, following a serious outbreak of measles in children of a religious sect during April, 2019, mandated application of the MMR measles vaccine (including mumps and rubella) to all their children to protect the general public. This was done over the religion leaders objections to vaccinations.

During 2018, Europe (53 countries) reported that measles killed 72 children and adults of the 82,500 people that contracted the measles virus due in part to a vaccination rate $(<90 \%)$ less than the $95 \%$ WHO deems necessary to prevent epidemics and in part to easily travel between countries. In a recent deadly outbreak, Madagascar is working to contain a measles epidemic that began in September, 2018 and by February, 2019 had killed more than 900 people (64\% children to age 14) and infected more than 68,000 persons. This epidemic is the result of a low immunization rate for many years and has spread throughout the country including Madagascar's most important seaport, Toamasina, and other ports of entry. This, in spite of the fact that a safe and effective vaccine, has been available for the past 50 years but whose application has not been mandated by the national government. Travelers from Madagascar to other countries are potential carriers for about 2 weeks ( 4 days before a rash appears, plus 6 days during the rash, and for 4 days after the rash disappears).

For this reason, the vaccination history of people entering a sea coast city or other ports of entry who come from or have passed through areas that are suffering or have suffered infectious disease events is important. This would require the collaboration of immigration officials who would be charged with checking the vaccination cards of people (ship personnel, tourists, immigrants, and asylum seekers) at sea coast city ports of entry. The same would be true for other ports of entry. It may require making spot checks of, for example, fever or an observational feature (sweating, paleness) of arriving passengers from specific locations suffering from outbreaks of infectious diseases. This was the case by fever checks in airports and other points of national entry after China revealed the spread of the SARS (severe acute, respiratory syndrome) infectious disease during 2002-2003. 


\subsection{Human Activities Sources of Non-Communicable Diseases}

Non-communicable diseases whether in highly and densely populated sea coast or inland cities can sicken and kill citizens. The focus on the causes of noncommunicable diseases (NCDs) that are responsible for 41 million of premature deaths annually and a far greater number of debilitating sicknesses has been on behavioral and metabolic causes and how to reduce their threats to societal health and its effect on city and national economies. These causes include tobacco use, alcohol abuse, poor nutrition, lack of exercise, obesity, and hypertension. Of the 41 million premature deaths cited above, $\sim 35$ million are in low and middle income countries. Seventy-nine percent of the NCDs are attributed to cardiovascular disease (17.9 million), cancer (9 million), respiratory disease (3.9) million, and diabetes (1.5 million). Public health education programs have to be continually implemented to reduce harmful behavior and causes [3].

\subsection{Pollution}

To this point in time, not enough attention has been given to pollution as a principal factor in NCDs illnesses and even premature deaths and their socio-economic consequences [4]. These are often expressed by a calculation of DALYS (disability adjusted life years), the total number of years lost to illnesses, disability, or premature deaths in a given population for a certain disease or disorder [5]. This can be a serious problem in high population sea coast and inland cities with high densities of citizens especially when there are edge neighborhoods with poor and marginalized people living in shantytowns/slums with unsafe water, lack of toilets, and problems with garbage/waste collection. The loss of productivity because of DALYS lowers GDP levels by up to $2 \%$ annually, especially in low middle income countries (incomes of US\$1026 to US\$4035), such as Bangladesh, Egypt, India, Indonesia, Pakistan, and Vietnam. Cities are most affected because they account for $85 \%$ of global economic business [6].

Pollution is a bane of humanity. Air, water, soil, and food pollutants contribute to the premature deaths of millions citizens and sickens many millions more from NCDs. Pollution-caused diseases accounted for about 9 million premature deaths in 2015 or $16 \%$ of all deaths globally (>56 million). Of the 9 million premature deaths, about $70 \%$ of these (e.g., cardiovascular disease, COPD) were from pollutioncaused NCDs, mainly in low income and low middle income countries [4].

Pollution is most damaging to people and economies where environmental laws protecting people and ecosystems from pollution have not been instituted or if laws have been passed but are not enforced. Pollution does not distinguish between sea coast and inland cities but as noted above is most damaging where there are high and dense populations breathing, drinking, and eating pollutant bearing matter. The 
effect of ingestion of pollutants that cause NCDs is not instantaneous but acts slowly over a period of time gradually attacking the normal functioning of body organs as pollutants access and bioaccumulate in them. Pollution can be greatly mitigated in three ways: (1) taxation has been effective in minimizing/eliminating the mass of pollutants emitted into the atmosphere or discharged into waterways or onto soils; (2) investment in pollutant capture and control equipment and safe disposal of the captured pollutants; and (3) legislation enforced by the threat and actions of closure of a pollutant-generating operation, by fines, or by incarceration of responsible individuals.

Of the $\sim 9$ million premature deaths caused by pollution, $\sim 7$ million are from indoor air pollution (2.9 million) and outdoor air pollution (4.2 million) [7]. There are 1.8 million people that die annually from water pollution (bacterial, viral, heavy metals) and 0.5 million from soils polluted with heavy metals and toxic chemicals (e.g., pesticides) ingested through foods. From an economic perspective, pollution frequency costs in the range of 4-5\% of a nation's GDP and for some this exceeds what they receive in development aid [8].

\subsubsection{Air Pollution}

Diseases that originate from indoor air pollution include stroke, coronary artery and ischemic heart diseases, chronic obstruction pulmonary disease (COPD), acute lower respiratory infections in children, and lung cancer. Outdoor air pollution diseases are much the same but with less coronary artery disease.

Sickness and deaths from indoor air pollution are the result of poor or no venting of gases and fine size particulates $(<2.5-10 \mu \mathrm{m})$ from the fuel used (e.g., soft coal, charcoal, wood, dried animal waste) for cooking and/or heating. Improved venting of indoor generated pollutants to the outside can reduce sickness and deaths especially for the more susceptible old people and small children but will add these toxins to outdoor air pollution. The effects of indoor air pollution can be eliminated by bringing natural gas to homes for cooking and heating and proper venting of emissions. This solution is lacking in some major sea coast and inland cities with highly populated shantytown/slum in inner city or edge neighborhoods.

Outdoor air pollution comes from multiple sources such as coal-burning power plants, various industries, vehicular traffic, and construction. These sources, individually or in consort, emit or raise fine size particulates $(<2.5-10 \mu \mathrm{m})$, and other toxic emissions into the air that include sulfur dioxide, nitrous oxide, and heavy metals (e.g., lead [Pb], mercury [Hg], arsenic [As], cadmium [Cd], and others). These toxic emissions may be inhaled or deposited onto soils or into waters where they can enter a food chain via agricultural crops (e.g., $\mathrm{Cd}$ in rice) and food fish (e.g., Hg in tuna, swordfish, king mackerel). Under some meteorological conditions, toxic emissions from industries and vehicular emissions will contribute to a sickening or killer smog. Air pollutant abetted diseases are most prevalent among major sea coast and inland cities with upwind nearby major industrial development 
and in shantytown/slum populations vs. economically more advantaged populations. The mandated use of pollutant capture and control technologies can mitigate the emissions of toxins from industrial sources cited and together with the inclusion of catalytic converters on vehicles can reduce the number of premature deaths abetted by outdoor air pollution. As cited previously, taxation of emission masses can mitigate the problem as can fines, plant closure until facilities becomes compliant with government legislative mandates, or the threat of imprisonment of plant owners [9].

Several major sea coast cities with high populations with very high and relatively high densities in developing countries suffer greatly from air pollution. These include Dhaka $\left(47,400\right.$ people $\left./ \mathrm{km}^{2}\right)$, Mumbai $\left(26,400 / \mathrm{km}^{2}\right)$, Abidjan $\left(13,700 / \mathrm{km}^{2}\right)$, Kolkata $\left(11,200 / \mathrm{km}^{2}\right)$, Jakarta $\left(9800 / \mathrm{km}^{2}\right)$, Ho Chi Minh City $\left(6800 / \mathrm{km}^{2}\right)$, Bangkok $\left(5200 / \mathrm{km}^{2}\right)$, Guangzhou $\left(5200 / \mathrm{km}^{2}\right)$, Zhangjiang $\left(5000 / \mathrm{km}^{2}\right)$, Tianjin $\left(4900 / \mathrm{km}^{2}\right)$, and Ningbo $\left(4000 / \mathrm{km}^{2}\right)$. In some of these cities, the air pollution threat is elevated by high numbers of poor populations living in shantytowns/slums where densities are higher than the average for a city and where the health status of a population is not as resistant to sickness and disease as it is in economically advantaged inner city populations. For example, in 6.5 million people of the Mumbai 23.3 million population live in shantytowns/slums as do 3.8 billion people of Kolkata's 13.3 million population. Similarly, of the 17.4 million population in Dhaka, 5.2 million live in shantytowns/slums. Perhaps most striking is that of the Lagos population of 14.8 million people, 8.8 million live in shantytowns/slums. In comparison to the densities of major coastal seaports, those in developed countries are generally less and without a significant slum populations (e.g., Rotterdam [3100/ $\left.\mathrm{km}^{2}\right]$, Hamburg

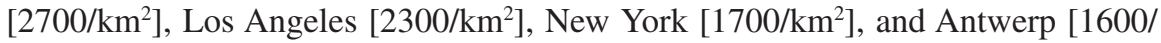
$\left.\mathrm{km}^{2}\right]$ ) [10].

Because of the concern for citizens health and the economic losses from workdays lost or even years of an individual's contribution to a nation's development lost, municipal governments have been monitoring air pollution and identifying specific sources of air-borne toxins. In some cases, they are enforcing existing legislation or carefully planning legislation with enforcement powers that mandate the use of best available technologies at all toxic emissions sources and safe disposal of the captured pollutants. If enforcement is applied, it will greatly reduce toxin loading of pollutants into the atmosphere and hence reduce the risk to the health and premature deaths of great numbers of people. This will be effective only if enforcement of laws curbing air pollution is not just an empty threat because of a nation's drive for continued economic development or because of a culture of corruption.

\subsubsection{Water Pollution}

Water pollution comes from the atmosphere as rain precipitates toxins from industrial emissions, especially coal-fired power plants and other sources into waterways or onto land where contaminants may run off into waterways. Water pollution 
comes as well from toxins in industrial effluents discharged onto land that can runoff into streams and rivers. Rainwater or streams that flow through talus piles of mine wastes can dissolve out heavy metals and carry them overland into waterways. Acid mine drainage from abandoned and functioning operations contaminates streams/rivers into which it discharges. Bacterial pollutants from human wastes where toilets are not used or where the wastes are collected but not treated can pollute waterways as do wastes and agricultural chemicals as runoff from farmland and commercial animal husbandry (e.g., cattle feed lots, chicken production). The toxin runoff, whatever the source(s), affects not only humans but ecosystems and their natural resources that are important to people. Contaminated waters can be cleansed to drinking standards by passing them through a treatment plant before distribution to consumers. Toxin-bearing surface runoff cited above can also seep through a surface cover into aquifers and contaminate groundwater. Under some conditions, groundwater can dissolve heavy metals that may be in aquifer rocks thus polluting water downflow from where the toxic metals originate. As with surface sources of water, polluted groundwater can be treated to remove a heavy metal pollutant or more than one, or other chemicals before being released for human use (drinking, cooking, personal hygiene) or for irrigation of food crops. The sickening of citizens in well-populated sea coast cities from ingestion of pollutants in unsafe drinking (and cooking) water is a grave concern especially in poor neighborhoods that lack access to clean water vs. economically advantaged neighborhoods that receive treated clean water [11].

\subsubsection{Soil to Food Pollution}

Sea coast and inland cities with large and growing populations (e.g., in the millions) obtain much of their foods from distant national and international sources. The reality is that some agricultural products (e.g., grains, vegetables, tobacco) may contain toxins taken up from soil or irrigation water polluted by human activities. These include heavy metals and pesticides/herbicides. If contaminated products are consumed over time, their toxin contents can build up in body organs (e.g., kidneys, lungs) and cause NCDs (see Sect. 6.3). Toxin build up can also disrupt the normal functioning of nervous and cardiovascular systems, and renewal of skeletal matter. The ingestion of human generated soil/food pollutants can cause NCDs [12-14].

In addition to soils being polluted by industrial and agricultural sources, soils can have natural high concentrations of potentially toxic metals. If a rock contains heavy metals (e.g., black shale) and a soil forms from it as it degrades and decomposes, contaminant metal(s) may be retained in the soil. One pathway to humans is ingestion of one or more of the potentially toxic metals taken up by agricultural crops (food or a non-edible product such as tobacco) being grown in a heavy metal polluted soil. Another pathway is from rainwater that seeps through a naturally contaminated soil that reacts with it to release a heavy metal that seeps through the soil into an underlying aquifer. Here, the path is toxic metal from rock to soil to 
agricultural products or drinking/cooking water that can do the same harm to the human body as noted in the previous paragraph by bioaccumulation in and damage to vital organs and also cause medical symptoms and the onset of a NCD. Examples of NCDs caused by heavy metal poisoning abound in the literature [12, 13].

Whether a NCD will develop from ingestion of a potently toxic metal depends on several factors. These are the dose absorbed by a body, the route and duration of exposure to chemical species that can cause chronic or acute illness, age, gender, genetics, and health conditions of exposed individuals. Perhaps most studied in recent years are cadmium $(\mathrm{Cd})$, lead $(\mathrm{Pb})$, arsenic $(\mathrm{As})$, mercury $(\mathrm{Hg})$, and chromium $(\mathrm{Cr})$. There are natural sources of potentially toxic metals (e.g., rocks containing arsenic-bearing minerals, ores, volcanic gases, and particulates). However, great masses of the heavy metal pollutant load in the atmosphere, water bodies, and soils come from human sources. These include industrial operations emissions and effluents, especially from coal-fired power plants, mining and smelters, and factories that manufacture batteries, pharmaceuticals, fertilizer and biocides, paper, pulp, and wood preservatives, among others. Sources for each metal or a group of metals that are thought to be linked to an epidemiology-defined disease node can be traced by following geological/geochemical principles used in the search for mineral deposits. Governments can then take action to greatly reduce or eliminate the source(s).

The fundamental question exists as to whether a government should make regular spot analyses to determine if there is a risk of heavy metal poisoning from agricultural food stuffs. In theory, the answer is yes. Realistically, however, analyses would be done but only after a heavy metal was identified fortuitously or if public health professionals detected symptoms of heavy metal poisoning in a population.

\subsection{Heavy Metal Pollutants Harmful to People and Ecosystems}

Heavy metals are important to industrial development as well as to human health. There are heavy metals that are essential micronutrients for the optimal functioning of biological processes and organs in humans in a quantity of a few milligrams ( $\mathrm{mg}$ ) or micrograms $(\mu \mathrm{g})$ daily. These are Fe (iron), Zn (zinc), Co (cobalt), As (arsenic), $\mathrm{Cr}$ (chromium), $\mathrm{Cu}$ (copper), Mn (manganese), Mo (molybdenum), Se (selenium), and V (vanadium). However, these may become toxic if ingested and bioaccumulated over time to higher concentrations than are necessary to satisfy nutritional needs. As noted in a previous paragraph, heavy metals that are most toxic to humans (+ animals and ecosystems) if ingested regularly in water and/or food are $\mathrm{As}, \mathrm{Pb}, \mathrm{Hg}$, and $\mathrm{Cd}$. These metals can bioaccumulate in a body and have toxic effects on different vital organs. In addition, they can interfere in the functioning of essential elements and their metabolic processes. These four heavy metals have been well-studied by toxicologists and other scientists for sources, mobility in ecosystems, and toxic effects. Their maximum allowable World Health Organization limits via oral intake in $\mu \mathrm{g} /$ day are $\mathrm{Pb}(10), \mathrm{Hg}$-inorganic (15), As-inorganic (15), and $\mathrm{Cd}(5)$ [15]. 
In the past and the present, old established sea coast cities have been centers of industrial development ofttimes within and/or upwind and upriver of cities. This, and increasing urbanization as populations grow, fueled increased utility and transportation needs. The release of heavy metals from industrialization, utility sources, and vehicles into a city environment and associated ecosystems on land and in the oceans can be an inherited legacy or existing danger to public health through bad air and contaminated water, soils, and foods. How sea coast cities (and inner ones) and national governments have adapted to mitigate toxic metal pollution is reflected in the health status of their populations.

\subsubsection{Lead: $P b$}

Lead represents an inherited legacy that is an existing health threat in and surrounding old homes from $\mathrm{Pb}$ in drinking water that passes through utility and home pipes containing $\mathrm{Pb}$ or pipes joined with $\mathrm{Pb}$-containing solder. This problem is being addressed by replacing the pipes, by regularly flushing and cleansing city water pipe networks, and by meeting WHO standards at treatment facilities. Lead bearing soil dust from vehicular sources has been basically eliminated since the phasing out of leaded gasoline that began in the 1970s and 1980s with the introduction of catalytic converters. However, inherited $\mathrm{Pb}$ in soils can be a health hazard. A city may opt to replace a soil, cover it, or otherwise remediate it especially at playgrounds. Cities were early in adapting to the $\mathrm{Pb}$-based paint problem by 1965 recommendations that the amount of $\mathrm{Pb}$ in interior and exterior paint be reduced to $<50 \%$ and subsequently to $<0.1 \%$ in 1997. The UN and World Bank aim to eliminate its use in 2020. A reasonable recommendation to deal with the millions of homes with $\mathrm{Pb}$-based paint is not to strip it off thus releasing toxic dust and chips to the air and surrounding soil but rather to repaint over it when the paint starts flaking. Lead reduction programs are essential to protect babies and small children who are especially threatened by $\mathrm{Pb}$ poisoning if they regularly ingest $\mathrm{Pb}$ through drinking water, hand to mouth transfer of contaminated soils, or chewing on flaking paint. Poisoning manifests itself by brain damage that can result in behavioral problems, learning deficits, and lowered IQ.

\subsubsection{Cadmium: $C d$}

Cadmium is an existential health danger, a known carcinogen. A principal source of the toxin is in rice grown in Cd-rich soils or irrigated with Cd-rich water. A public outcry arose in 2013 in Guangzhou, China, a port city of 14.5 million people, when a report revealed that the rice tested in 8 of 18 samples from local markets had $\mathrm{Cd}$ concentrations above China's national food safety standards. Citizens were upset because of the knowledge that a long-term bioaccumulation of $\mathrm{Cd}$ in the body had 
been linked to chronic kidney disease/failure, the bone diseases osteoporosis and osteomalacia, diabetes, lung disease, impairment, cardiovascular disease, and cancer [15-17]. Rice is a staple food for close to half the world's population ( 3.8 billion people) especially for poor populations in low and low middle income countries and its purity has to be assured. About $90 \%$ of the consumption is in Asia, with a rising demand in Africa and Latin America, regions with a great number of commercially important sea coast cities. Awareness of the potential problem has resulted in spot checks of rice crops to assure their purity. Scientists are studying how to reduce the bioavailability of $\mathrm{Cd}$ in a soil (paddy or not) to growing plants rice grains, by adjusting the $\mathrm{pH}$ of the growing medium [18, 19]. Geneticists that have improved micronutrient contents in rice crops and the plant tolerance to pests and herbicides are researching low $\mathrm{Cd}$-accumulating rice cultivars growing in $\mathrm{Cd}$-rich soils. These may reveal a gene that damps Cd uptake. Once identified, genetic engineers can modify receptive rice species that will greatly reduce uptake of soil Cd yet maintain their nutritional values. Cadmium can also access a body by inhaling cigarette smoke from tobacco grown in Cd-rich soils.

\subsubsection{Arsenic: As}

Arsenic has been shown to be the cause of chronic and NCDs in many countries with commercially important and high/densely populated port cities, especially in Bangladesh, India, Pakistan, Thailand, Vietnam, Taiwan, and China. Contaminated drinking water and cooking with untreated or insufficiency treated aquifer water is a principal source of the toxin. The As may develop within an aquifer as conditions change with water drawdown during growing season permitting oxidation and release from a mineral in aquifer rock into the water as either the oxidized chemical species arsenite $\left(\mathrm{As}^{3+}\right)$ or arsenate $\left(\mathrm{As}^{5+}\right)$. Both species can be toxic if enough is ingested but the $\left(\mathrm{As}^{3+}\right)$ form is 60 times more toxic [20]. The chronic response to As poisoning may be the appearance of lesions as pinkish to tan or skin colored papules and keratosis, an epidermal wart-like growth. Acute afflictions caused by the longterm As bioaccumulation are cancer of the lungs, liver, bladder, or skin $[12,15]$. The World Health Organization warned that more than 200 million people are at risk of As poisoning from aquifer water. Water treatment facilities can eliminate this problem if installed, supplied with necessary cadres and chemical supplies, and maintained with a clean water distribution network that reaches all of a population.

\subsubsection{Mercury: $\mathrm{Hg}$}

Mercury in food fish is an existing public health threat. Mercury emitted into the atmosphere from industrial sources, especially coal-fired power plants, rains into the oceans where microorganisms in the marine food chain convert it to the very 
toxic methyl mercury form $\left(\mathrm{CH}_{3} \mathrm{Hg}^{+}\right)$[21]. This chemical bioaccumulates in prey of large predator food fish (e.g., king mackerel, swordfish, tuna, tilefish, orange roughy, shark, marlin, and escolar) that further concentrate it to levels that can harm humans that regularly eat them. Shellfish bioaccumulate the toxin as well. Sea coast populations include much fish/shellfish in their diets, especially poorer citizens that count on fish/shellfish for $20 \%$ of their protein nourishment and $50 \%$ of their calorie intake. Mercury intake can be especially dangerous to pregnant women or women that breast feed their infants because the $\mathrm{CH}_{3} \mathrm{Hg}^{+}$can pass to a growing fetus or an infant and cause neural damage. In adults, $\mathrm{Hg}$ poisoning can manifest itself as tremors, memory problems, depression, or diminished hearing and vision. Governments recommend how much $\mathrm{Hg}$ accumulating fish meat is safe to eat. For example, Canada recommends that pregnant women limit their intake to $150 \mathrm{~g} / \mathrm{month}$ (5 1/4 oz), youngsters 5-11 years old eat no more than $125 \mathrm{~g} / \mathrm{month}(\sim 41 / 2 \mathrm{oz})$, and children 1-4 years old eat no more than $75 \mathrm{~g} / \mathrm{month}(\sim 21 / 2 \mathrm{oz})$. These values vary with the food fish eaten [22].

Lastly, it should be noted that there is a possible legacy source of heavy metal toxins or other pollutants: buried/hidden toxic wastes. These are disposal sites left by long gone industries in or near long established sea coast (and inner) cities. As urban centers grow to accommodate expanding populations ( 2.8 billion more people in 2050 than in 2019), perhaps 700 million added to port cities, areas to be urbanized should first be assessed to assure that no buried/hidden toxic waste disposal sites are present that could, over time, release toxins into an inhabited zone and pose a danger to people. If detected, such sites must be cleaned up before habitation is allowed.

\section{References}

1. Wikipedia. Köppen climate classification. www.wikipedia.org/wiki/Köppen_climate_ classification

2. Claude KM, Underschultz J, Hawkes MT (2018) Ebola virus epidemic in war-torn estern DR Congo. Lancet 392:1399-1401. https://doi.org/10.1016/S0140-6736(18)32419-X

3. WHO (2018) Noncommunicable diseases. www.who.int

4. Fuller R, Rahona E, Fisher S, Caravanos J, Webb D, Kass D, Matte T, Landrigan PJ (2018) Pollution and non-communicable disease: time to end the neglect. Lancet 2(3):e96-e98

5. National Institute of MentalHealth. What are DALYS?. www.nimh.gov/dalys

6. Landrigan PJ, Fuller R, Acosta NJR, Nereus JR, Adeyl O, Arnold R, Basu NN, Baldé AB, Bertollini R, Bose-O'Reilly S, Boufford JI, Breysse PN, Chiles T, Mahidol C, Coll-Seck AM, Cropper ML, Fobil J, Fuster V, Greenstone M, Haines A, Hanrahan D, Hunter D, Khare M, Krupnick A, Lanphear B, Lohani B, Martin K, Mathiasen KV, McTeer MA, Murray CJL, Ndahimananjara JD, Perera F, Potočnik J, Preker AS, Ramesh J, Rockström J, Salinas C, Samson LD, Sandilya K, Sly PD, Smith KR, Steiner A, Stewart RB, Suk WA, van Schayck OCP, Yadama GN, Yumkella K, Zhong M (2018) The Lancet Commission on pollution and health. Lancet 391:462-512.

7. World Health Organization (2014) News release: 7 million premature deaths annually linked to air pollution. www.who.int/mediacentre/news/release/2014/air-pollution/en/ 
8. World Bank Group, Independent Evaluation Group (2017) Towards a clean world for all: an IEG evaluation of the World Bank Group's support for pollution management. World Bank, Washington, DC, unpaginated

9. World Health Organization (2016) Ambient air pollution: a global assessment of exposure and burden of disease. WHO, Geneva, 131p. apps.who.int/iris/bitstream/10665/ 250141/1/9789241511353

10. Demographia (2018) World urban areas (built up urban areas or world agglomerations). www. demographia.com/db-worldua.pdf

11. World Health Organization (2011) Guidelines for drinking-water quality, 4th edn. WHO, Geneva, 541p. apps.who.int/iris/bitstream/10665/44584/1/9789241548151

12. Tchoumwou PB, Yediou CG, Patiolla AK, Sutton DJ (2012) Heavy metals, toxicity and the environment. A review. EXS 101:133-164. www.ncbi.nlm.nih.gov/pmc/articles/PMC4144270/

13. Jaishankar M, Tseten T, Anbalagan N, Mathew BB, Beeregowda KN (2014) Toxicity, mechanism and health effects of some heavy metals. Interdiscip Toxicol 7:60-72. www.ncbi.nim.nih. gov/pmc/articles/PMC4427717/

14. Rizwan M, Ali S, Andrees M, Rizvi H, Zia-ur-Rehman M, Hannan F, Qayyum MF, Hadeez F, Ok YS (2016) Cadmium stress in rice: toxic effects, tolerance mechanisms, and management: a critical review. Environ Sci Pollut Res Int 23:17859-17879

15. Govind P, Madhurt S (2014) Heavy metals causing toxicity in animals and fishes. Res J Anim Vet Fish Sci 2:17-23

16. South China Morning Post (2013) High cadmium levels found in Guangzhou rice, South China. www.scmp.com/china/article/1240198/

17. Kobayashi I, Hagino N (1965) Strange osteomalacia by pollution from cadmium mining. Progress report WP 00359, Okayama University, pp 10-24

18. Kanu AS, Ashraf U, Bangura A, Yang DM, Ngaujah S, Tang X (2017) Cadmium (Cd) stress in rice; photo-availability, toxic effects and mitigation measures - a critical review. J Environ Sci Toxicol Food Technol 1:7-23. www.josr/journals.org

19. Chen H, Zhang W, Yang Y, Wang P, McGrath SP, Zhao F-J (2018) Effective method to reduce cadmium accumulation in rice grain. Chemosphere 207:699-707

20. Nordstrom DK (2002) Worldwide occurrence of arsenic in groundwater. Science 296:2143-2145

21. Pirrone N, Cinderella S, Feng X, Finkelman RB, Friedli HR, Leaner J, Mason R, Mukherjee AB, Stracher GB, Streets DG, Telmer K (2010) Global mercury emissions to the atmosphere from anthropogenic and natural sources. Atmos Chem Phys 10:5951-5964

22. Health Canada (2017) Mercury in fish. Consumption advice: making informed choices about fish. Health Canada, Ottawa, unpaginated 